\title{
E-SCIENCE E POLÍtICAS PÚBLICAS BRASILEIRAS
}

\author{
E-SCIENCE AND BRAZILIAN PUBLIC POLICY
}

E-SCIENCE Y POLÍTICAS PUBLICAS BRASILEÑAS

Gildenir Carolino Santos ${ }^{1}$

Universidade Estadual de Campinas - Sistema de Bibliotecas

\section{Correspondência}

${ }^{1}$ Gildenir Carolino Santos iD

Universidade Estadual de Campinas - Sistema de Bibliotecas

Campinas, SP

E-mail: gilbfe@unicamp.br

Submetido em: $24-07-2018$

Aceito em: 30-07-2018

Publicado em: 28-08-2018

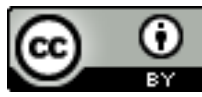

JITA: FJ. Knowledge management

(C) RDBCI: Rev. Digit. Bibliotecon. Cienc. Inf.

Campinas, SP

v. 16

n. 3

p.440-443

set./dez. 2018 


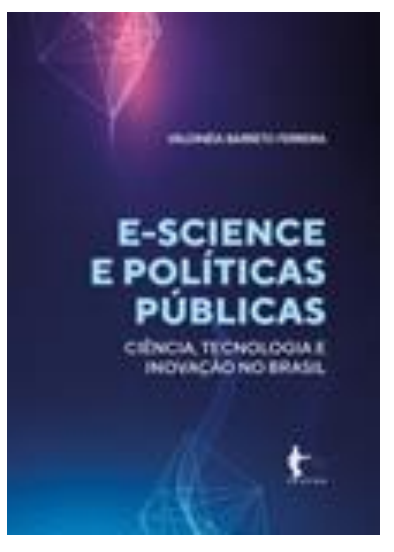

FERREIRA, Valdinéia Barreto. e-Science e políticas públicas para ciência, tecnologia e inovação no Brasil. Salvador: EDUFBA, 2018. 256 p. ISBN 978$85-232-1707-517$ x $24 \mathrm{~cm}$.

O livro "E-science e políticas públicas para ciência, tecnologia e inovação no Brasil", elaborado pela bibliotecária Valdinéia Barreto Ferreira, apresenta o conceito que está relacionado à melhoria e fortalecimento dos laboratórios e grupos de pesquisa como ambientes colaborativos. Além disso, discute ao longo dos capítulos, questões que dizem respeito a políticas públicas para fomento científico, tecnológico e de inovação e também dos institutos nacionais de ciência e tecnologia, entre outros aspectos.

Valdinéia Barreto Ferreira fez o doutorado e o mestrado em Ciência da Informação pela Universidade Federal da Bahia (UFBA). É graduada em Biblioteconomia e Documentação, também pela UFBA. Especialista em Administração Pública com aprofundamento em Gestão pela Universidade Estadual de Feira de Santana (UESF), além de ser especialista em Gestão Universitária e Qualidade em Serviços pela UFBA. Valdinéia é bibliotecária e membro do Núcleo Científico do Sistema Universitário de Bibliotecas da UFBA. Membro da Rede de Inovação Tecnológica do Nordeste (Rede NIT-NE). Foi coordenadora do Sistema de Bibliotecas do Tribunal de Justiça do Estado da Bahia e ministra aulas e palestras sobre busca e recuperação da informação científica eletrônica e normalização de trabalhos técnico-científicos.

Nessa obra, publicada pela EDUFA, com 256 páginas, ligada a área das Ciências Sociais, que teve seu lançamento ocorrido em junho de 2018, foi fruto do seu doutorado, concluído em 2016. A autora "busca pelo entendimento de termos e conceitos como eScience, práticas colaborativas para inovação, Nanotecnologia e políticas públicas para CT\&I, esses carregados de subjetividades e encorpados por um poder revolucionário, foi o sinal de alerta de que o conhecimento a eles pertinente precisava vir à tona”.

Assim, com a realização de pesquisas que visam identificar práticas colaborativas contemporâneas na ciência, as quais ocorrem nos ambientes colaborativos institucionais, é recorrente na agenda de estudo de diversos domínios científicos. Esses estudos agregam alguns dos elementos que caracterizam o fazer científico contemporâneo repleto de atores e atuantes. 
A autora buscou analisar a e-Science e as práticas colaborativas voltadas à inovação e a ela associadas, no âmbito dos Institutos Nacionais de Ciência e Tecnologia (INCTs) da área de Nanotecnologia, apoiados pelo Programa Nacional de Ciência e Tecnologia.

Dessa forma, a obra possui prefácio, apresentação e apêndices, além de estar dividida em 8 (oito) capítulos, a saber:

"e-Science", focando na compreensão conceitual, origem e base fundante da e-Science, além de modelo de infraestrutura. No capítulo seguinte a autora descreve as "Políticas públicas para fomento científico, tecnológico e de inovação". Na sequência é enfocada "A prática colaborativa: tradição e contemporaneidade", apresentando a colaboração, práticas, tradição, contemporaneidade e fios que tecem uma rede colaborativa. Em outro capítulo sobre "Fazer científico e tecnológico" é relatado às tramas da teoria ator-rede. No capítulo "Nanotecnologia e sua importância no contexto brasileiro" à autora trata do mundo das nanoestruturas: conceito, origem e fundamentos da Nano tecnologia. A autora dá destaque a um capítulo específico sobre os "Institutos nacionais de ciência e tecnologia de nanotecnologia" focando a identificação dos INCTs e informantes; perfil dos pesquisadores; natureza do grupo e descrição de 10 (dez) institutos nacionais. No penúltimo capítulo sobre "Práticas e redes colaborativas para inovação nos INCTs da área de nanotecnologia", são mencionadas as práticas colaborativas nos INCTs; as redes de práticas colaborativas para inovação; a produção científica dos pesquisadores dos INCTs de Nanotecnologia e a infraestrutura e suporte para pesquisa: INCTs e modelo e-Science. No último capítulo é dada uma atenção sobre a "Evidência de práticas colaborativas, produção científica e EScience”. Fecha-se com a Conclusão. As referências apesar de serem as mesas apresentada na tese, estão atualizadas e adequadas para a temática do livro.

É um trabalho muito bem escrito, e rico no conceito de e-Science, termo que também pode ser interpretado e traduzido como e-Ciência no caso do Brasil. Em seu conceito prático, o termo é utilizado para se referir a métodos de obtenção de resultados científicos através da utilização de computação intensiva, usualmente paralela, e/ou grande volume de dados. Para os estudiosos dessa área essa área, podemos considerar essa publicação como uma espece de manual da ciência eletrônica.

Para convalidar essa obra com o que está se falando no estado de São Paulo à respeito de e-Science, a FAPESP - Fundação de Amparo à Pesquisa do Estado de São Paulo, vem desenvolvendo desde 2013, ano da criação do Programa FAPESP de Pesquisa em e-Science, vem conceituando terminologicamente que a:

e-Science é um nome dado em todo o mundo a pesquisas que são realizadas em todas as áreas do conhecimento e que têm necessidade de lidar com grandes volumes de dados ou de usar métodos computacionais sofisticados e computação de alto desempenho. A pesquisa em e-Science aborda todas as etapas de um processo de pesquisa -- desde a criação de ferramentas computacionais que ajudem cientistas a formular problemas de pesquisa, coletar e analisar dados, até a modelagem, a simulação, a divulgação e o reuso dos resultados da pesquisa. Mas não basta, para isso, aplicar técnicas computacionais já existentes, uso de tecnologias padrão, prestação de serviços de assistência de informática ou cessão e utilização de dados. Pesquisa em e-Science pressupõe trabalho conjunto e multidisciplinar, em que cientistas da Computação auxiliem pesquisadores de outras áreas a desenvolver

v. 16

n. 3

p. $440-443$

set./dez. 2018 
pesquisas de forma mais rápida e eficiente e que, nessa parceria, a Computação também seja feita de forma inovadora, transformadora. ${ }^{1}$ (grifo nosso).

Além disso, a autora destaca o papel das políticas públicas para o desenvolvimento da C\&TI no Brasil.

A obra é recomendada para pesquisadores, estantes, bibliotecário de dados e aficionados pela ciência eletrônica em todas as áreas.

\section{Referência}

FERREIRA, Valdinéia Barreto. e-Science e políticas públicas para ciência, tecnologia e inovação no Brasil. Salvador: EDUFBA, 2018. 256 p. ISBN 978-85-232-1707-5 17 x 24 cm

\footnotetext{
${ }^{1}$ Disponível em: http://www.fapesp.br/publicacoes/2015/folder escience.pdf
} 